\title{
Hydrogen effects on mechanical property and microstructure of a Zr-based metallic glass composite
}

\author{
G.H. Duan ${ }^{\mathrm{a}, \mathrm{b}}$, M.Q. Jiang ${ }^{\mathrm{b}, \mathrm{c}}$, X.F. Liu ${ }^{\mathrm{b}, \mathrm{c}}$, L.H. Dai ${ }^{\mathrm{b}, \mathrm{c}}$, J.X. Li ${ }^{\mathrm{a}, *}$ \\ ${ }^{a}$ Key Laboratory of the Ministry of Education (MOE) for Environmental Fracture, Corrosion and Protection Center, University of Science and Technology Beijing, Beijing \\ 100083, China \\ ${ }^{\mathrm{b}}$ State Key Laboratory of Nonlinear Mechanics, Institute of Mechanics, Chinese Academy of Sciences, Beijing 100190, China \\ ${ }^{\mathrm{c}}$ School of Engineering Science, University of Chinese Academy of Sciences, Beijing 100049, PR China
}

\section{A R T I C L E I N F O}

\section{Keywords:}

Metallic glass composite

Hydrogen embrittlement

Mechanical property

Stacking faults

\begin{abstract}
A B S T R A C T
Effects of hydrogen on the mechanical property and microstructure evolution are investigated on a Zr-based metallic glass composite contains both metallic glass matrix and body centered cubic (bcc) dendrite crystal. The compressive strength to failure descreased from $2.2 \mathrm{GPa}$ to $1.9 \mathrm{GPa}$; the fracture strain decreased from $39 \%$ to $26 \%$. The composite retains a moderate compressive strength and strain after hydrogenation. The composite shows certain resistance of hydrogen embrittlement. Neither nanocrystallization in amorphous matrix nor amorphization in $b c c$ dendrite crystal is detected. But there are so many stacking faults in the bcc dendrite crystal after hydrogen charging. Hydrogen lowers the value of stacking fault energy and promotes planar slip of the dendrite crystal. Planar slip and slip localization accelerate the deformation of the dendrite crystal and lead to premature fracture of the composite. The experimental results are consistent with the hydrogen enhanced local plasticity mechanism of hydrogen embrittlement.
\end{abstract}

\section{Introduction}

Hydrogen embrittlement is one of important modes of material failure in engineering applications. The interaction of hydrogen with metals has been studied extensively in crystalline alloys. Up to now, mechanisms for hydrogen embrittlement in crystalline alloys have been basically clarified, including hydrogen-induced decohesion, metal hydride formation and hydrogen-enhanced localized plasticity [1-3].

Metallic glasses belong to amorphous alloys with long-range disordered arrangement of atoms. They are attractive for outstanding properties in elasticity, strength and toughness [4-7]. It is also important to study the effects of hydrogen on metallic glasses due to their potential uses for hydrogen storage and purifying. It has been shown that many metallic glasses are of susceptibility of hydrogen embrittlement [8-15]. The underlying mechanisms also include hydrogen-induced decohesion, metal hydride formation, etc. Metallic glass often contains high content of active metal elements such as $\mathrm{Zr}$, Ti and Ni. They are prone to form metal hydrides due to interaction with hydrogen atoms $[16,17]$. Jayalakshmi et al. [8,9] found that the presence of hydrogen in $\mathrm{Zr}_{50} \mathrm{Ni}_{27} \mathrm{Nb}_{18} \mathrm{Co}_{5}$ and $\mathrm{Ni}_{59} \mathrm{Zr}_{16} \mathrm{Ti}_{13} \mathrm{Nb}_{7} \mathrm{Sn}_{3} \mathrm{Si}_{2}$ causes both the expansion of the amorphous structure and the formation of hydride nanocrystalline phases. The latter promotes easy crack initiation and accelerates the embrittling effect. However, Suh's works [10-12] have indicated that metal hydride formation is not involved in the hydrogen embrittlement of a Zr-Ti-Ni-Cu-Be bulk metallic glass. On the contrary, the hydrogen just affects atomic movement and short-rang structure. Actually, hydrogen atoms might occupy a wide variety of interstitial sites, resulting from a distribution of both chemical and geometrical configurations in the amorphous structure [13,14].

Introduction of dentrite crystalline phases to metallic glass matrix to form the composite is a good strategy for the plasticity or ductility enhancement [18-21]. Despite extensive investigations on the properties of $\mathrm{Zr}$-and Ti-based metallic glass composites, the hydrogen effects on their mechanical properties and structures have been rarely concerned, but for work by Jayalakshmi et al. [22]. They found that the present of hydrogen in a $\mathrm{Ti}_{50} \mathrm{Zr}_{25} \mathrm{Cu}_{25}$ composite results in reduction in strength, elastic modulus, and fracture strain. In addition, hydrogeninduced amorphization is observed in the crystal phase, but nanocrystallization is not detected in the glass matrix. The introduction of hydrogen induces lattice expansion of the metallic atoms result by the slight shift in diffraction peak toward lower angles in XRD pattern, hydrogen reduces cohesion in both metallic glass matrix and bcc crystal. Hydrogen embrittlement is mainly attributed to the decohesion between metallic atoms. As a typical composite material with excellent

\footnotetext{
* Corresponding author.

E-mail address: jxli65@ustb.edu.cn (J.X. Li).
} 
mechanical properties, Zr-based metallic glass composites have attracted much attention. Whether these mechanisms of hydrogen embrittlement for Ti-based composites are applicable to Zr-based metallic glass composites. Mechanisms for hydrogen embrittlement include hydrogen-induced decohesion, metal hydride formation and hydrogenenhanced localized plasticity. Which mechanism is dominant to the $\mathrm{Zr}$ based metallic glass composites deserves further investigation.

The aim of present work is to study the hydrogen embrittlement of a typical Zr-based metallic composite. Structural morphologies of the composite by hydrogenation are analysised. We examine the decohesion between metallic atoms, the hydrogen-induced nanocrystallization in glass matrix and hydrogen-induced amorphization in dendritic crystal. Whether the hydrogen atom will have influence on the plastic deformation of metal glass matrix and BCC crystal, and further affect the fracture procedure of the composites. The underlying mechanisms for hydrogen embrittlement are discussed.

\section{Experimental procedure}

Alloys were designed according to the pseudo-ternary phase diagram with apexes of $\mathrm{Zr}, \mathrm{Ti}+\mathrm{Nb}$, and $\mathrm{Be}_{9} \mathrm{Cu}_{5} \mathrm{Ni}_{4}$ [23,24]. The composition $\left(\mathrm{Zr}_{75} \mathrm{Ti}_{25} 5_{100-\mathrm{x}} \mathrm{Nb}_{\mathrm{x}}\right)_{100-\mathrm{y}}\left(\mathrm{Be}_{50} \mathrm{Cu}_{27.5} \mathrm{Ni}_{22.5}\right)_{\mathrm{y}}$ with $\mathrm{x}=10$ and $\mathrm{y}=20\left(\mathrm{Zr}_{60} \mathrm{Ti}_{12} \mathrm{Nb}_{8} \mathrm{Ni}_{4.5} \mathrm{Cu}_{5.5} \mathrm{Be}_{10}\right)$ was prepared, which yields a duplex phase microstructure containing $\beta$-phase dendrites in a glass matrix. Ingots of $\mathrm{Zr}_{60} \mathrm{Ti}_{12} \mathrm{Nb}_{8} \mathrm{Ni}_{4.5} \mathrm{Cu}_{5.5} \mathrm{Be}_{10}$ (mole fraction, \%) were prepared by arc melting the mixture of high-purity $\mathrm{Zr}, \mathrm{Ti}, \mathrm{Nb}, \mathrm{Cu}, \mathrm{Ni}$, and $\mathrm{Be}$ elements (>99.9 wt\%) under a Ti-gettered argon atmosphere. Afterwards, the ingots were crushed into pieces and remelted by induction under a high pure argon atmosphere, and rods with $8 \mathrm{~mm}$ in diameter and about $60 \mathrm{~mm}$ in length were obtained by suctioning the melt into the copper mould. The samples were machined to cylinder with $5 \mathrm{~mm}$ in diameter and $10 \mathrm{~mm}$ in length, then ground with 600 grit emery paper to remove layer of oxide, and part of samples were hydrogen charged in a $1 \mathrm{~mol} / \mathrm{L} \mathrm{H}_{2} \mathrm{SO}_{4}+1 \mathrm{~g} / \mathrm{LCH}_{4} \mathrm{~N}_{2} \mathrm{~S}$ solution with current density of $20 \mathrm{~mA} / \mathrm{cm}^{2}$ for $48 \mathrm{~h}$. Hydrogen concentration in the cylinder sample was measured by G4 PHOENIX. Compressive experiments were conducted on specimens as cast and after $48 \mathrm{~h}$ hydrogen charging with MTS810 testing machine, all at a strain rate of $5 \times 10^{-4} \mathrm{~s}^{-1}$.

The structure morphologies, fracture surfaces and profiles near the failure surfaces were observed by JSM-IT300 scanning electron microscopy (SEM). Phase analysis was performed on Rigaku smartlab (9) Xray diffraction (XRD) (Cu k $\alpha$ radiation). Structures of the composites as cast and after $48 \mathrm{~h}$ hydrogen charging were observed by transmission electron microscopy (TEM). One sample was hydrogen precharged in a $1 \mathrm{~mol} / \mathrm{L} \mathrm{H}_{2} \mathrm{SO}_{4}+1 \mathrm{~g} / \mathrm{LCH}_{4} \mathrm{~N}_{2} \mathrm{~S}$ solution with current density of $20 \mathrm{~mA}$ / $\mathrm{cm}^{2}$ for $48 \mathrm{~h}$, with $1 \mathrm{~mm}$ in thickness and $8 \mathrm{~mm}$ in diameter. For verifying hydrogen effect to the structure, a thin film sample with only $20 \mu \mathrm{m}$ in thickness was hydrogen precharged with the same current density and time to ensure sufficient hydrogen in the sample, and its structure was examined by high resolution transmission electron microscopy (HRTEM). Deformation microstructures after compression are examined by TEM to seek for deformation mechanisms on the cross section plane of sample As cast and After $48 \mathrm{~h}$ hydrogen charging.

\section{Results and discussion}

The microstructure of the sample is checked to be metallic glass composite, by SEM observation. As shown in Fig. 1, The light bright area is $b c c$ dendrite crystal phase, and the dark gray matrix is amorphous phase. Bcc dendrite crystals distribute equably in metallic glass matrix. A limited amount hydrogen concentration of $3.29 \mathrm{ppm}$ is obtained from $48 \mathrm{~h}$ hydrogen charged cylinder sample. The limited amount of hydrogen from high electric current long time charging may be the result of the limited hydrogen pickup capacity restricted by oxidation of zirconium alloys surface $[25,26]$.

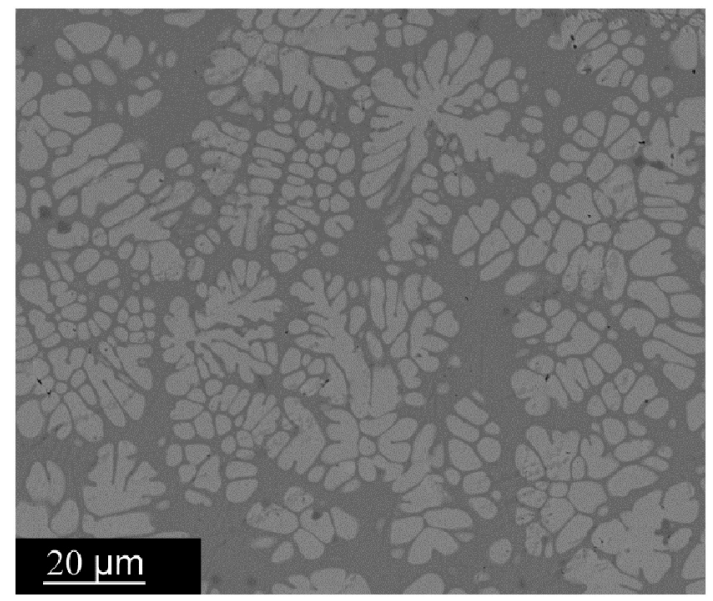

Fig. 1. SEM image of $\mathrm{Zr}_{60} \mathrm{Ti}_{12} \mathrm{Nb}_{8} \mathrm{Ni}_{4.5} \mathrm{Cu}_{5.5} \mathrm{Be}_{10}$.

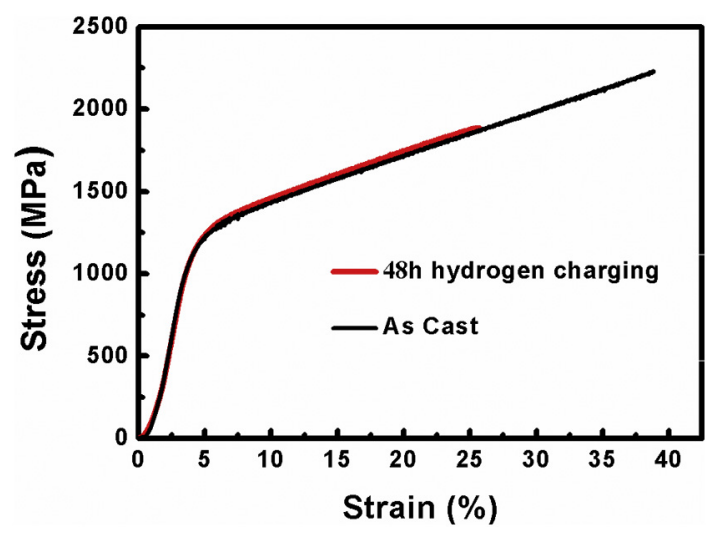

Fig. 2. The compressive engineering stress-strain curves of the composite. As cast and After $48 \mathrm{~h}$ hydrogen charging.

\subsection{Mechanical property}

Typical compression stress-strain curves of the composites are shown in Fig. 2. Before and after hydrogen charging, the composites maintains the constant slope in the elastic stage, and both yield at a stress level of about 1.1 GPa and exhibit obvious strain hardening after yielding. The as-cast composite fractures at a compressive strength of $2.2 \mathrm{GPa}$ with fracture strain of $39 \%$. The composite fractures at a compressive strength of $1.9 \mathrm{GPa}$ after hydrogen charging, with a fracture strain of $26 \%$. The compressive strength and strain to failure descreased by $14 \%$ and $33 \%$ respectively, the composite holds a moderate compressive strength and strain after hydrogenation. The composite shows certain resistance of hydrogen embrittlement.

Fig. 3 presents the SEM morphologies of fracture surface and profiles near the failure surface. For the as-cast composite, the failure angle is about $44.2^{\circ}$. The precharged composite shows a failure angle of about $42.9^{\circ}$. The relatively larger deviation from the maximum shear stress direction $\left(45^{\circ}\right)$ is consistent with the plasticity decrease in the precharged specimen. This composite exhibits different fracture features before and after hydrogenation. The composite as cast shows a characterized plastic flow morphology of droplet-like patterns in Fig. 3(a). As presented in previous work $[18,27,28]$, temperature burst in shear band propagation of metallic glass is sufficiently high to provoke local melting. Material in the shear band flows like a fluid. Contrast to the rough traces of shear flow of the origin composite in Fig. 3(a), (c) shows a mixture of plastic flow and more flat brittle feature on the fracture surface after hydrogen charging. The plastic flow fracture morphology on the sample indicates that the crystalline phase still have the effect to hinder shear band propagation. The crystalline phase induce stress 

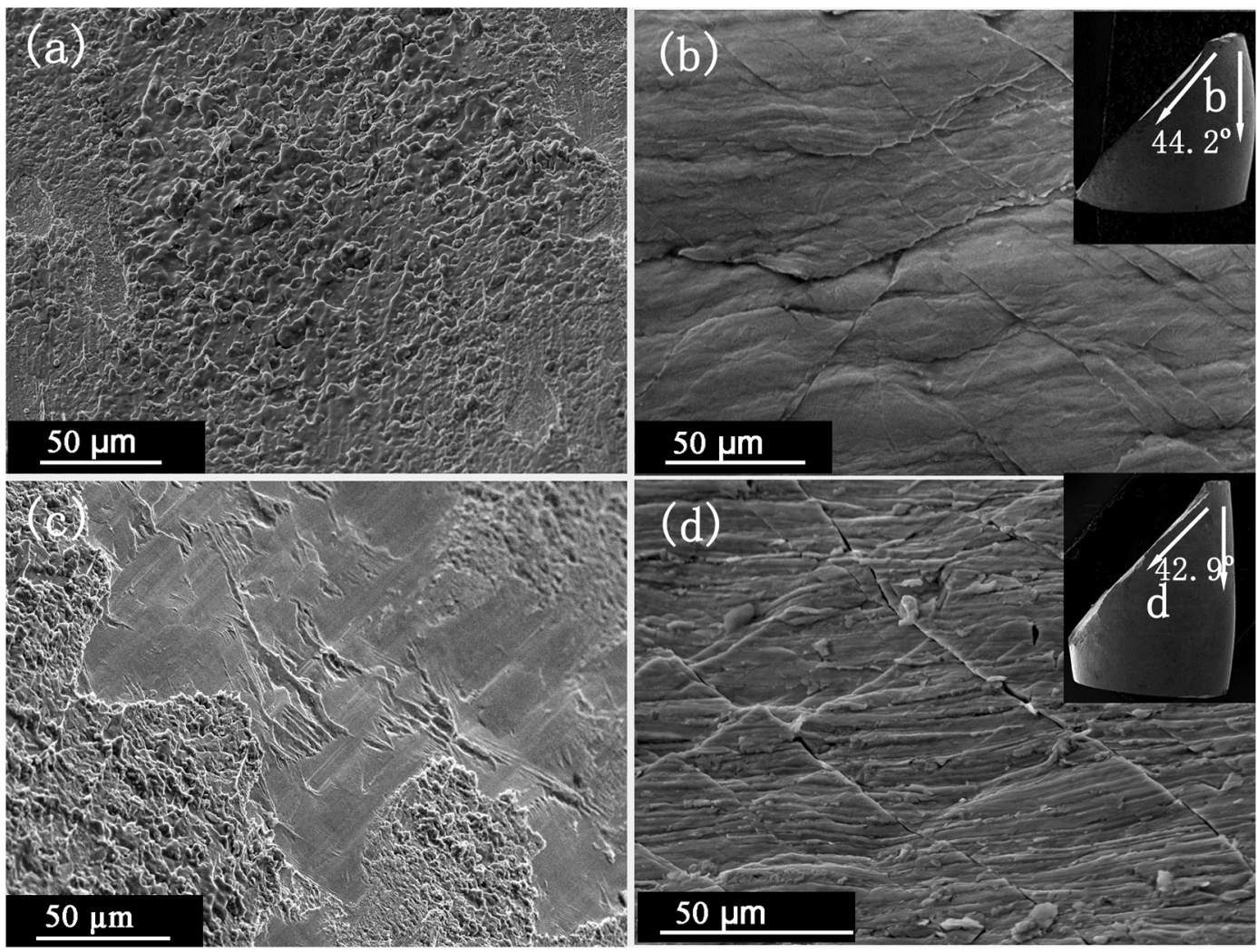

Fig. 3. SEM morphology of $\mathrm{Zr}_{60} \mathrm{Ti}_{12} \mathrm{Nb}_{8} \mathrm{Ni}_{4.5} \mathrm{Cu}_{5.5} \mathrm{Be}_{10}$ fracture surface and profiles near the failure surface. (a) fracture surface of As cast, (b) profile of As cast, (c) fracture surface After $48 \mathrm{~h}$ hydrogen charging,. (d) profile After $48 \mathrm{~h}$ hydrogen charging.

concentration at the interface of crystalline phase and the amorphous matrix during shear bands propagation and drive multiple shear bands of $\mathrm{Zr}_{60} \mathrm{Ti}_{12} \mathrm{Nb}_{8} \mathrm{Ni}_{4.5} \mathrm{Cu}_{5.5} \mathrm{Be}_{10}$. As shown in Fig. 3(b) and (d), multiple shear bands distribute on profiles near the failure surfaces before and also after hydrogen charging. Shear band arrays extend along habit planes oriented roughly at $45^{\circ}$ to the loading axis of the sample, multiple shear bands arrays prevail and intersect, resulting in enormous plasticity of the composite as cast and also after hydrogen charging.

According to the SEM observations, the plastic flow morphology of the as-cast sample indicates that the compression fracture process is controlled by the shear banding interaction of metallic glass matrix. The crystalline phase hinders shear band propagation, resulting in the formation of shear band arrays [18,29-32]. The fractography shows a mixture of plastic flow and more brittle flat feature morphology on the sample after hydrogen charging. A more flat feature on the fracture surface indicates the brittle fracture after hydrogen charging, which is consistent with the decreased fracture strength and strain after hydrogenation.

\subsection{Structural analyses}

The XRD diffraction patterns are shown in Fig. 4. Before charging, the sharp diffraction peaks for the crystalline phase are superimposed on the broad diffuse diffraction peaks. The crystalline phase is checked to be the $\beta$-Zr phase with a $b c c$ structure. After charging, the diffraction peaks show no obvious changes in amorphous matrix and also crystalline phases. Crystal lattice parameters do not change obviously. The brittle flat feature indicates that the hydrogen addition may induce loss of cohesion between metallic atoms in the amorphous matrix, which cause the deceased compression properties. However, XRD patterns show no expansions of the amorphous structure and crystal lattice parameters, and hydrogen enhanced decohesion is not detected in our experiments.

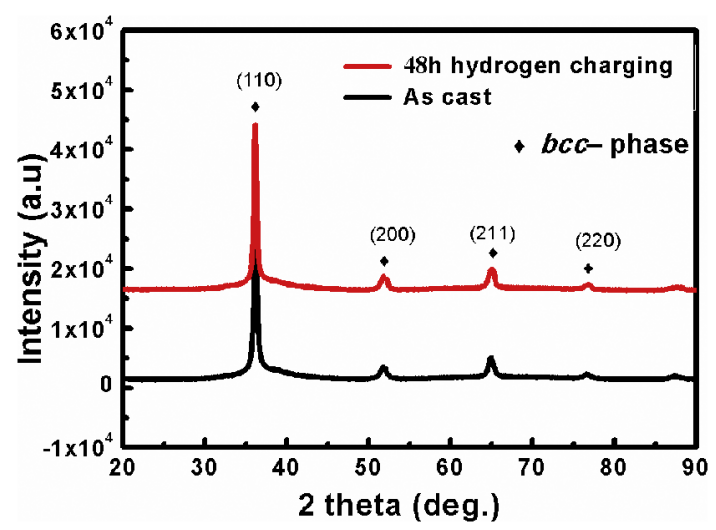

Fig. 4. The XRD patterns of $\mathrm{Zr}_{60} \mathrm{Ti}_{12} \mathrm{Nb}_{8} \mathrm{Ni}_{4.5} \mathrm{Cu}_{5.5} \mathrm{Be}_{10}$. As cast and After $48 \mathrm{~h}$ hydrogen charging.

Fig. 5 shows the TEM morphology of of the $\mathrm{Zr}_{60} \mathrm{Ti}_{12} \mathrm{Nb}_{8} \mathrm{Ni}_{4.5} \mathrm{Cu}_{5.5} \mathrm{Be}_{10}$ composite. Before hydrogen charging The oval area in specimen in Fig. 5(a) shows the crystalline phase with a bcc structure, which is confirmed by the lattice pattern. The matrix region shows an amorphous state, corresponding to the diffraction rings. Fig. 5(b) shows the microstructure after $48 \mathrm{~h}$ hydrogen charging. Neither amorphization in dentritic crystalline phase or nano hydride formation in metallic glass matrix is observed, which is calibrated diffraction pattern of bcc crystal (BCC) and metallic glass phase (MG) after $48 \mathrm{~h}$ hydrogen charging, respectively. TEM observations do not detect any phase change due to the hydrogenation, which agrees with the results of XRD in Fig. 4.

To clarify whether longtime hydrogen charging can induce hydride formation in the composite, a $20 \mu \mathrm{m}$ thin film specimen was hydrogen charged for $48 \mathrm{~h}$. TEM images of the composite and corresponding 


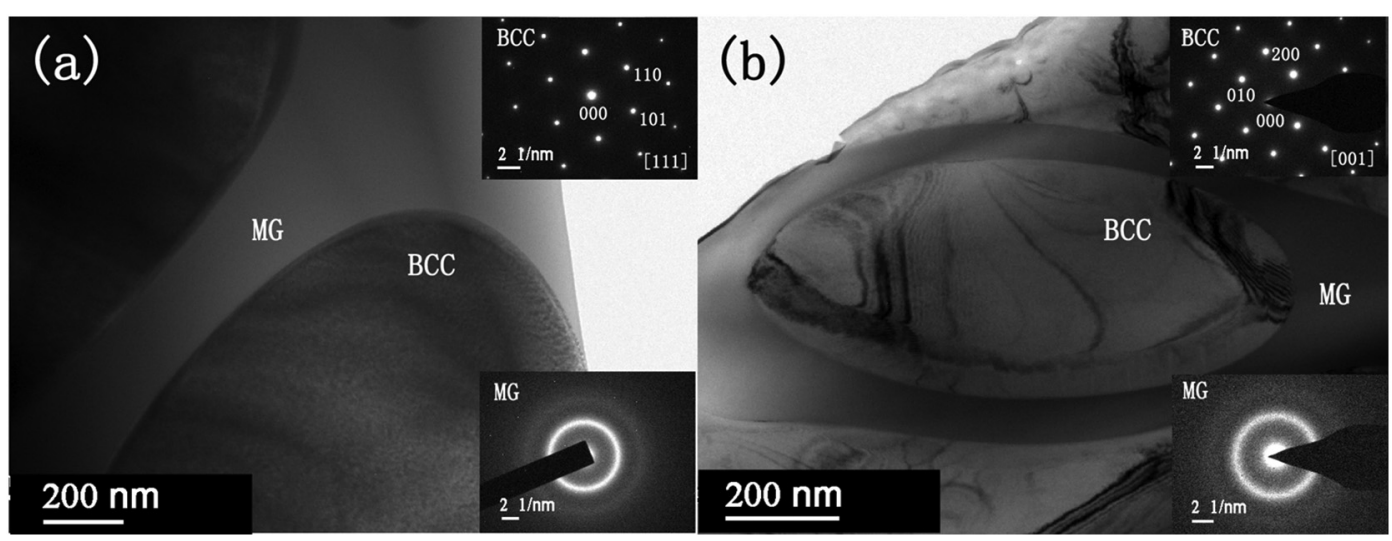

Fig. 5. TEM images of $\mathrm{Zr}_{60} \mathrm{Ti}_{12} \mathrm{Nb}_{8} \mathrm{Ni}_{4.5} \mathrm{Cu}_{5.5} \mathrm{Be}_{10}$ Alloys and diffraction pattern of bcc crystal (BCC) and metallic glass phase (MG). (a) Alloys of As cast, (b) Alloys after $48 \mathrm{~h}$ hydrogen charging.

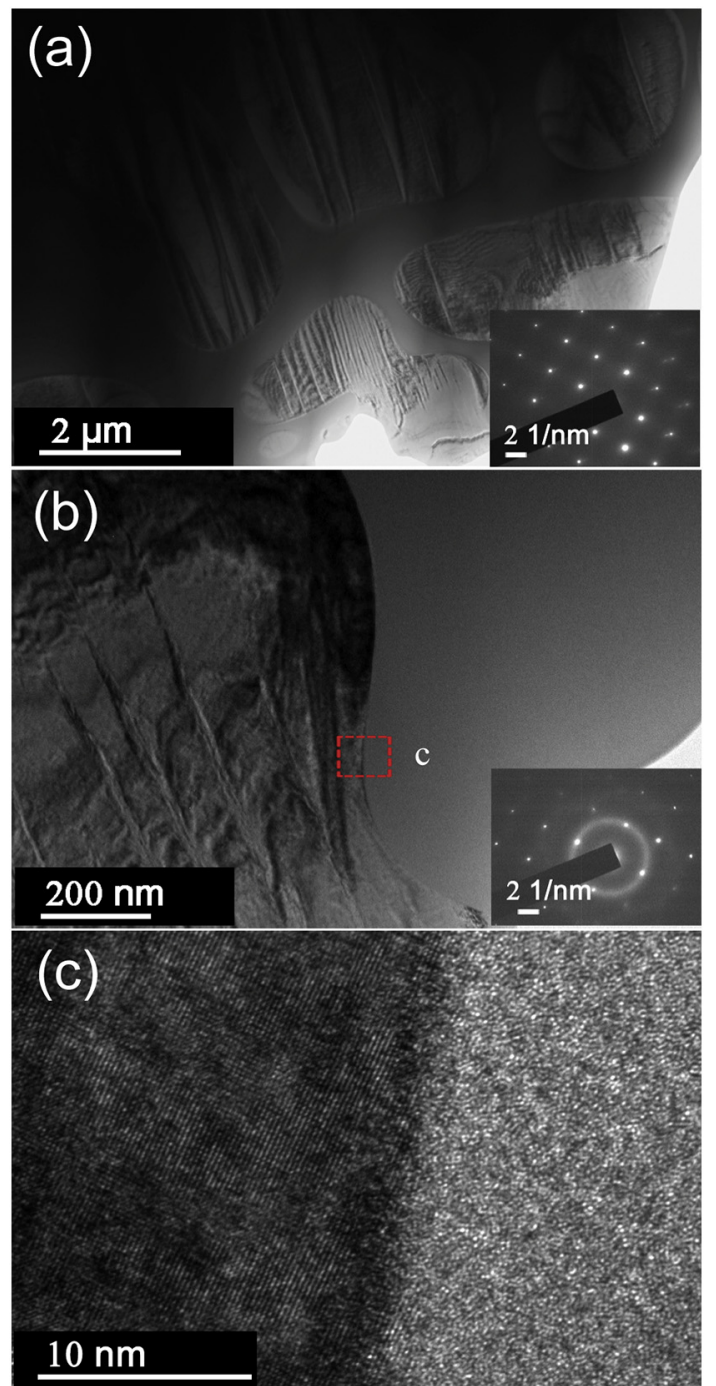

Fig. 6. TEM images of $\mathrm{Zr}_{60} \mathrm{Ti}_{12} \mathrm{Nb}_{8} \mathrm{Ni}_{4.5} \mathrm{Cu}_{5.5} \mathrm{Be}_{10}$ with a thickness of $20 \mu \mathrm{m}$ after $48 \mathrm{~h}$ hydrogen charging. (a) TEM images of the composite, (b) TEM image of the interface, (c) HRTEM of the interface.

SAED pattern are presented in Fig. 6. TEM images of the composite in Fig. 6(a) and the interface of the bcc phase and the amorphous matrix in 6(b) shows no new phase formed by hydrogenation. HRTEM image of the interface of metallic glass matrix and bcc crystal in Fig. 6(b) is presented in Fig. 6(c). It verifies the absence of hydride formation, and both $b c c$ crystalline phase and amorphous phase maintain their respective microstructure. But stacking faults are observed in $b c c$ dendrite crystals. As shown in Figs. 6(a) and 6(b), the stacking faults distribute all over the $b c c$ phase of this composite and are along (110) plane of $b c c$ phase.

Effects of hydrogen on decreasing SFE are discussed in crystal material [33-36]. Hydrogen-induced formation of stacking faults is found in the $f c c$ phase of stainless steel $[37,38]$ and also bcc metals $[39,40]$. Stacking faults by hydrogenation are observed along the (101) planes of Ti-V-Mn $b c c$ alloy. SFE decreases by the formation of $\mathrm{H}-\mathrm{H}$ pairs in the fault-zone, and Stacking faults are formed by self-accommodation due to shear stress during hydrogenation [40]. In the present $\mathrm{Zr}_{60} \mathrm{Ti}_{12} \mathrm{Nb}_{8} \mathrm{Ni}_{4.5} \mathrm{Cu}_{5.5} \mathrm{Be}_{10}$ sample with a thickness of $20 \mu \mathrm{m}$ after $48 \mathrm{~h}$ hydrogen charging, hydrogenation is enhanced by long time concentrated hydrogen charging in the thin specimen. Stacking faults origin from accumulation of $\mathrm{H}-\mathrm{H}$ pairs in fault-zone.

\subsection{Deformation mechanisms}

Fig. 7 presents the deformation microstructure of $\mathrm{Zr}_{60} \mathrm{Ti}_{12} \mathrm{Nb}_{8} \mathrm{Ni}_{4.5} \mathrm{Cu}_{5.5} \mathrm{Be}_{10}$ on the cross section plane of sample after compression. For the as cast composite, as shown in Fig. 7(a) and (b), Highly dense dislocations scatter at the grain boundaries of the bcc crystal, and deformation twins are observed in the bcc phase. In the hydrogen charged composite, the dislocations tangled and a dislocations bands was found in Fig. 7(c), thin and straight twins were formed, as shown in Fig. 7(d). These twins should be new mechanical twins formed during the deformation. The deformation twins are surrounded by high density dislocations, they are parallel with each other and expand through the whole $b c c$ phase. Dislocation and deformation twinning contribute the deformation mechanism and work harding capability of the composite. In the as cast sample, the deformation twins are more separated to nucleated and facilitated the deformation of the composite. But in the hydrogen charged composite, deformation of dislocation and twins are prone to expand planarly.

\subsection{Discussion}

For the $\mathrm{Zr}_{60} \mathrm{Ti}_{12} \mathrm{Nb}_{8} \mathrm{Ni}_{4.5} \mathrm{Cu}_{5.5} \mathrm{Be}_{10}$ composite as cast, upon compression loading, the dendrites yield first, and slip systems in dendrites become active and readily accommodate the plastic strain. Dislocation accumulation in plastic strain in dendrite, pile-ups of dislocations and scattered deformation twinning constitute the plastic strain of the $b c c$ phase. $B C C$ dendrites hinders shear band propagation and promote formation of multiple shear bands at the interface of dendrites and glass matrix. The strain energy accumulated during the plastic deformation and causes a temperature burst sufficiently high to provoke local 


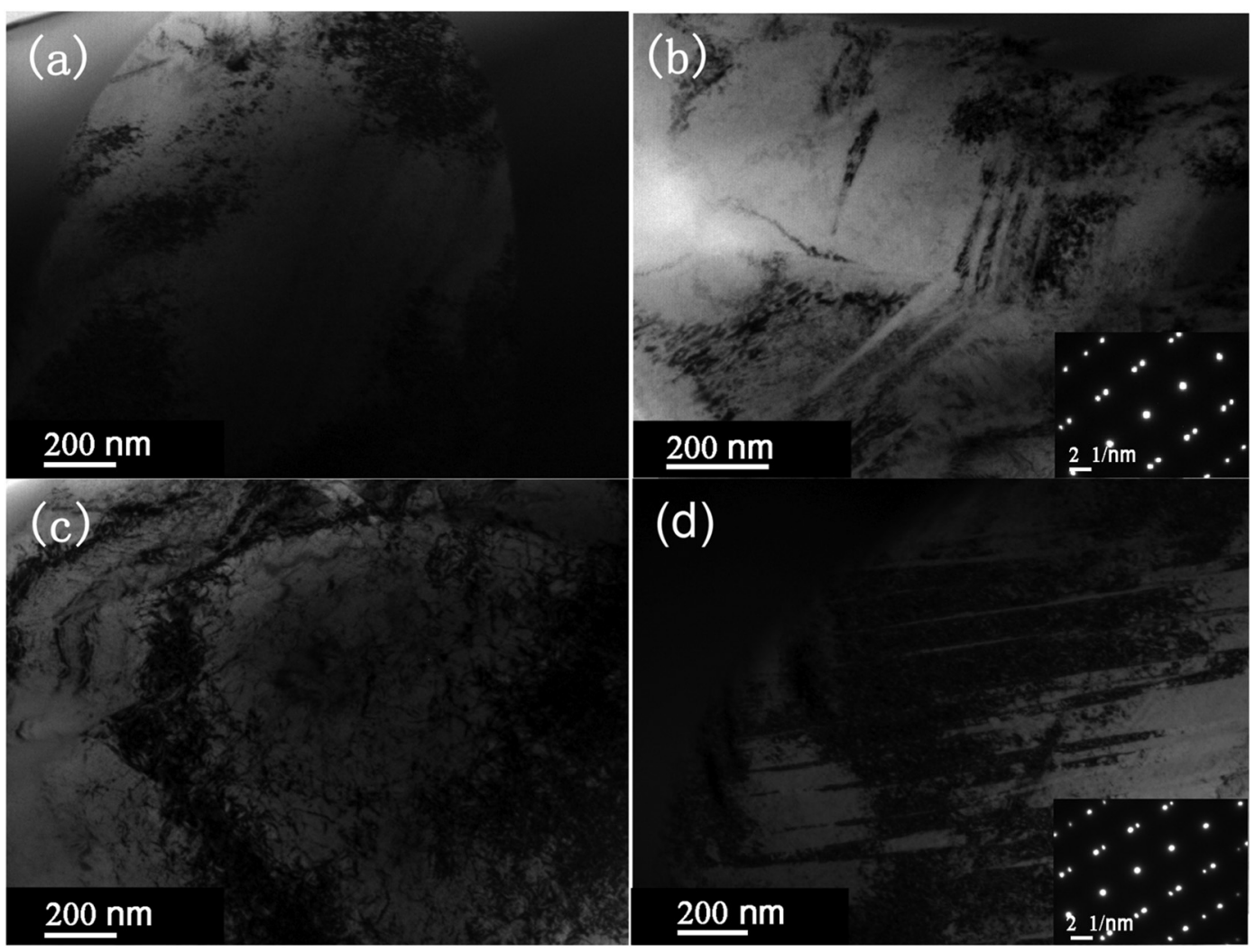

Fig. 7. TEM deformation microstructure of $\mathrm{Zr}_{60} \mathrm{Ti}_{12} \mathrm{Nb}_{8} \mathrm{Ni}_{4.5} \mathrm{Cu}_{5.5} \mathrm{Be}_{10}$ after compression As cast (a, b) and After 48 h hydrogen charging(c, d). (a) tangled dislocations of the composite As cast. (b) deformation twins of the composite As cast. (c) tangled dislocations of the composite After $48 \mathrm{~h}$ hydrogen charging, (d) planar deformation twins of the composite After $48 \mathrm{~h}$ hydrogen charging.

melting before fracture. As presented by the fracture morphology of the composite in Fig. 3(a), the fracture of the composite As cast is dominated by the plastic flow from the metallic glass matrix.

For the hydrogen charged composite, the plastic strain in dendrites and multiple shear intersections caused by the two-phase interface remain, which confirms the composite fractures at a moderate compression strength and strain. But the compression procedure is more affected by planar slip and slip localization of the bcc crystal. Firstly, As shown in Fig. 6, the present of hydrogen-induced stacking faults confirms that hydrogen reduces stacking fault energy. Lower stacking fault energy can cause dislocations to split into extended dislocations and prevent dislocations from cross slip, cross slip is restrained, planar slip is enhanced [36]. Planar and straight twins are favored. Moreover, hydrogen enhances dislocation mobility and promotes splitting of dislocations. Increases in dislocation mobility will enhance slip localization and localization of deformation [41]. An inhomogeneous distribution of hydrogen and hydrogen clusters in the crystal accelerate slip localization. Dislocation plane slips and gathers to form high density dislocation zones. High density of dislocations and laminar twins form in the straining of the composite. High density of dislocations and laminar twins affect mutually and expand through the bcc crystal. Dislocations are constrained in the laminar twin bands of the bcc crystal. Deformation is concentrated, a local stress concentration develops, crack initiates and propagates along the planar slip plane in the dendrites and eventually throughout the matrix. Planar slip of dislocations and slip localization of the bcc crystal accelerate the compress fracture process and ultimately induce the flat fracture morphology and a restricted strain of the composite. The effect of hydrogen on $\mathrm{Zr}_{60} \mathrm{Ti}_{12} \mathrm{Nb}_{8} \mathrm{Ni}_{4.5} \mathrm{Cu}_{5.5} \mathrm{Be}_{10}$ composite is mainly from enhanced dislocation mobility and the slip localization of the crystalline phase. The experimental results are consistent with the hydrogen-enhanced local plasticity mechanism of hydrogen embrittlement [34-37].

\section{Conclusions}

Effects of hydrogen on the mechanical property of a Zr-based metallic glass composite $\mathrm{Zr}_{60} \mathrm{Ti}_{12} \mathrm{Nb}_{8} \mathrm{Ni}_{4.5} \mathrm{Cu}_{5.5} \mathrm{Be}_{10}$ are investigated through quasi-static compressive experiments. The following conclusion can be obtained.

1) The composite fractures at a moderate compressive strength and strain after hydrogenation. The composite shows certain resistance of hydrogen embrittlement.

2) No hydrogen-induced nanocrystallization in amorphous matrix or hydrogen-induced amorphization in dendrite crystalis detected after hydrogenation.

3) Stacking faults are observed in $b c c$ dendrite crystal phase after hydrogen charging. Hydrogen lowers stacking faults energy, promotes planar slip of the $b c c$ crystal. Planar slip of the dendrite crystal and slip localization lead to premature fracture of the composite. The experimental results are consistent with the hydrogen-enhanced local plasticity mechanism of hydrogen embrittlement.

\section{Acknowledgments}

This work was supported by the National Nature Science Foundation of China (Grant Nos.U1760203, 11522221 and 51571029).

\section{Declaration of interests}

The authors declare that they have no known competing financial interests or personal relationships that could have appeared to influence the work reported in this paper.

The authors declare the following financial interests/personal relationships which may be considered as potential competing interests. 


\section{Competing interests}

The author declare no competing interests.

\section{References}

[1] T. Neeraj, R. Srinivasan, J. Li, Hydrogen embrittlement of ferritic steels: observations on deformation microstructure, nanoscale dimples and failure by nanovoiding, Acta Mater. 60 (2012) 5160-5171.

[2] T. Michler, J. Naumann, Microstructuralaspects upon hydrogen environment embrittlement of various bcc steels, Int. J. Hydrog. Energy 35 (2010) 821-832.

[3] J. Song, W.A. Curtin, Mechanisms of hydrogen-enhanced localized plasticity: An atomistic study using $\alpha$-Fe as a model system, 68 (2014) 61-69.

[4] J.F. Wang, R. Li, N.B. Hua, T. Zhang, Co-based ternary bulk metallic glasses with ultrahigh strength and plasticity, J. Mater. Res. 26 (2011) 2072-2079.

[5] M.F. Ashby, A.L. Greer, Metallic glasses as structural materials, Scripta. Mater. 54 (2006) 321-326.

[6] W.H. Wang, C. Dong, C.H. Shek, Bulk metallic glasses, Mater. Sci. Eng. R 44 (2004) 45-89.

[7] M.D. Demetriou, M.E. Launey, G. Garrett, J.P. Schramm, D.C. Hofmann, W.L. Johnson, R.O. Ritchie, A damage-tolerant glass, Nature. Mater. 10 (2011) 123-128.

[8] S. Jayalakshmi, S.O. Park, K.B. Kim, E. Fleury, D.H. Kim, Studies on hydrogen embrittlement in Zr- and Ni- based amorphous alloys, Mater. Sci. Eng. A 449 (2007) 920-923.

[9] S. Jayalakshmi, K.B. Kim, E. Fleury, Effect of hydrogenation on the structural, thermal and mechanical properties of Zr50-Ni27-Nb18-Co5 amorphous alloy, J. Alloys Compd. 417 (2006) 195-202.

[10] D. Suh, R.H. Dauskardt, Hydrogen effects on the mechanical and fracture behavior of a Zr-Ti-Ni-Cu-Be bulk metallic glass, Scripta. Mater. 42 (2000) 233-240.

[11] D. Suh, R.H. Dauskardt, The effects of hydrogen on deformation and fracture of a Zr-Ti-Ni-Cu-Be bulk metallic glass, Mater. Sci. Eng. A 319 (2001) 480-483.

[12] D. Suh, P. Asoka-Kumar, R.H. Dauskardt, The effects of hydrogen on viscoelastic relaxation in $\mathrm{Zr}-\mathrm{Ti}-\mathrm{Ni}-\mathrm{Cu}-\mathrm{Be}$ bulk metallic glasses: implications for hydrogen embrittlement, Acta Mater. 50 (2002) 537-551.

[13] N. Eliaz, D. Eliezer, An overview of hydrogen interaction with amorphous alloys, Adv. Perform. Mater. 6 (1999) 5-31.

[14] K. Aoki, X.G. Li, T. Masumoto, Factors controlling hydrogen-induced amorphization of C15 Laves compounds, Acta. Metal. Mater. 40 (1992) 1717-1726.

[15] G.B. Shan, Y.W. Wang, W.Y. Chu, J.X. Li, X.D. Hui, Hydrogen damage and delayed fracture in bulk metallic glass, Corros. Sci. 47 (2005) 2731-2739.

[16] A. Gebert, N. Ismail, U. Wolff, M. Uhlemann, L. Schultz, Effects of electrochemical hydrogenation of Zr-based alloys with high glass-forming ability, Intermet 10 (2002) 1207-1213.

[17] Y.Z. Liu, S.Y. Qiu, P. Kang, X.Q. Huang, X.T. Zu, Effects of hydrogen on the mechanical properties of Ti-Al-Zr alloy, J. Alloys Compd. 384 (2004) 145-151.

[18] C.C. Hays, C.P. Kim, W.L. Johnson, Microstructure controlled shear band pattern formation and enhanced plasticity of bulk metallic glasses containing in situ formed ductile phase dendrite dispersions, Phys. Rev. Lett. 84 (2000) 2901-2904.

[19] J.W. Qiao, In-situ dendrite/metallic glass matrix composites: a review, Mater. Sci Technol. 29 (2013) 685-701.

[20] Y. Wu, Y.H. Xiao, G.L. Chen, C.T. Liu, Z.P. Lu, Bulk metallic glass composites with transformation-mediated work-hardening and ductility, Adv. Mater. 22 (2010) $2770-2773$.
[21] Y. Wu, D.Q. Zhou, W.L. Song, H. Wang, Z.Y. Zhang, D. Ma, X.L. Wang, Z.P. Lu, Ductilizing bulk metallic glass composite by tailoring stacking fault energy, Phys. Rev. Lett. 109 (2012) 245506.

[22] S. Jayalakshmi, J.P. Ahn, K.B. Kim, E. Fleury, Hydrogen-induced amorphization and embrittlement resistance in Ti-based in situ composite with bcc-phase in an amorphous matrix, J. Mater. Res. 22 (2007) 428-436.

[23] F. Szuecs, C.P. Kim, W.L. Johnson, Mechanical properties of $\mathrm{Zr}_{56.2} \mathrm{Ti}_{13.8} \mathrm{Nb}_{5.0} \mathrm{Cu}_{6.9} \mathrm{Ni}_{5.6} \mathrm{Be}_{12.5}$ ductile phase reinforced bulk metallic glass composite, Acta.Mater. 49 (2001) 1507-1513.

[24] X.F. Liu, Y. Chen, M.Q. Jiang, P.K. Liaw, L.H. Dai, Tuning plasticity of in-situ dendrite metallic glass composites via the dendrite-volume-fraction-dependent shear banding, Mater. Sci. Eng. A 680 (2017) 121-129.

[25] M. youssef, M. Yang, B. Yildiz, Doping in the valley of hydrogen solubility: a route to designing hydrogen-resistant zirconium alloys, Phys. Rev. Applied. 5 (2016) 2173-2179.

[26] A. Couet, A.T. Motta, R.J. Comstock, Hydrogen pickup measurements in zirconium alloys: relation to oxidation kinetics, J. Nucl. Mater. 451 (2014) 1-13.

[27] J.H. Chen, M.Q. Jiang, Y. Chen, L.H. Dai, Strain rate dependent shear banding behavior of a Zr-based bulk metallic glass composite, Mater. Sci. Eng. A 576 (2013) 134-139.

[28] H.J. Leamy, H.S. Chen, T.T. Wang, Plastic flow and fracture of metallic glass, Metall.Trans. 3 (1972) 699-708.

[29] E. Pekarskaya, C.P. Kim, W.L. Johnson, In situ transmission electron microscopy studies of shear bands in a bulk metallic glass based composite, J. Mater. Res. 16 (2001) 2513-2518.

[30] J.W. Qiao, Y. Zhang, P.K. Liaw, G.L. Chen, Micromechanisms of plastic deformation of a dendrite/Zr-based bulk-metallic-glass composite, Scripta.Mater. 61 (2009) 1087-1090.

[31] G. Chen, J.L. Cheng, C.T. Liu, Large-sized Zr-based bulk-metallic-glass composite with enhanced tensile properties, Intermet 28 (2012) 25-33.

[32] J.S.C. Jang, T.H. Li, P.H. Tsai, J.C. Huang, T.G. Nieh, Critical obstacle size to deflect shear banding in Zr-based bulk metallic glass composites, Intermet 64 (2015) 102-105.

[33] V.G. Gavriljuk, V.N. Shivanyuk, J. Foct, Diagnostic experimental results on the hydrogen embrittlement of austenitic steels, Acta Mater. 51 (2003) 1293-1305.

[34] M. Koyama, C.C. Tasan, E. Akiyama, K. Tsuzaki, D. Raabe, Hydrogen-assisted decohesion and localized plasticity in dual-phase steel, Acta Mater. 70 (2014) 174-187.

[35] J.D. Hermida, A. Roviglione, Stacking fault energy decrease in austenitic stainless steels induced by hydrogen pairs formation, Scripta. Mater. 39 (1998) 1145-1149.

[36] Y.L. You, Q.Q. Teng, Z. Zhang, Q.P. Zhong, The effect of hydrogen on the deformation mechanisms of $2.25 \mathrm{Cr}-1$ Mo low alloy steel revealed by acoustic emission, Mater. Sci. Eng. A 655 (2016) 277-282.

[37] M. Hatano, M. Fujinami, K. Arai, H. Fujii, M. Nagumo, Hydrogen embrittlement of austenitic stainless steels revealed by deformation microstructures and strain-induced creation of vacancies, Acta Mater. 67 (2014) 342-353

[38] H. Luo, Z.M. Li, Y.H. Chen, D. Ponge, M. Rohwerder, D. Raabe, Hydrogen effects on microstructural evolution and passive film characteristics of a duplex stainless steel, Electrochem. Commun. 79 (2017) 28-32.

[39] P. Torres, K. Aoyagi, T. Suda, S. Watanabe, S. Ohnuki, Hydride formation and fracture of vanadium alloys, J.Nucl.Mater. 307-311 ( (2002) 625-629.

[40] J. Matsuda, Y. Nakamura, E. Akib, Microstructure of Ti-V-Mn bcc alloys before and after hydrogen absorption-desorption, J. Alloys Compd. 509 (2011) 4352-4356.

[41] H.K. Birnbaum, p. Sofronis, Hydrogen-enhanced localized plasticity-a mechanism for hydrogen-related fracture, Mater. Sci. Eng. A 176 (1994) 191-202. 